\section{The Future Use and Development of Expert System Technology in Horticulture}

\author{
R.M. Crassweller ${ }^{1}$ J.W. Travis ${ }^{2}$, \\ P.H. Heinemann ${ }^{3}$, and \\ E.G. Rajotte ${ }^{4}$
}

Additional index words. computers, decision support systems, technology transfer, expert systems

Summary. Decreasing resources and increasing complexity of horticultural crop production necessitate that new technologies be developed to transfer information to commercial producers. Expert systems (ES) have been cited as potential tools that can facilitate knowledge transfer. The definitions of an expert system, however, technically only indicates a computer program that simulates the thought processes of a human expert and, as such, does not supply all the facets necessary to assist commercial producers. The combination of databases, graphic capabilities, and textual information into a comprehensive program would provide a more complete package. To differentiate the two, we use the term decision support systems (DSS). The development, testing, and release of DSS, however, require greater commitment and interdisciplinary cooperation. Developing DSS fosters interstate, interregional, and international cooperation among researchers and extension personnel. Using systems developed in fruit production as examples, we outline the value of DSS to promote cooperation, the resources necessary to develop these systems; and the attitudinal change necessary to build the systems.

The Pennsylvania State University, University Park, PA 16802-4200.

Associate Professor, Department of Horticulture. ${ }^{2}$ Associate Professor, Department of Plant Pathology. ${ }^{3}$ Assistant Professor, Department of Biological and Agricultural Engineering.

${ }^{4}$ Associate Professor, Department of Entomology.

\section{The problem}

Fruit production is a complex business requiring technical knowledge of agricultural economics, agricultural engineering, entomology, horticulture, and plant pathology. The number of government regulations also adds to its complexity. The complexity of all agricultural production systems is rapidly exceeding the capability of producers to manage adequately and economically (Sullivan et al., 1989). Unfortunately, in the past few years, the ability of the Cooperative Extension system to assist farmers in dealing with these changes is handicapped by limited human and financial resources. Federal and state support of extension and research programs in horticultural and agronomic crops is declining in the United States and around the world (Funt and Nicholson, 199 1; Poling et al., 1991).

Traditional forms of extension delivery and education can inhibit the implementation of new site-specific integrated pest management (IPM) strategies to growers. IPM involves multiple methods to solve problems in agriculture, including cultural, chemical, biorational, genetic, and mechanical control tactics; as well as a good economic and environmental assessment of each control alternative. Detailed site-specific pest, crop, and soil information is required to arrive at an informed pest management decision. Barely are all these elements provided by a single individual. In reality, IPM practitioners must consult numerous experts or references. Gerber (1989) noted that traditional extension techniques fail to integrate these various disciplines when considering the farm system as a whole. Individual growers must act as their own interpreters and compilers of a wide range of disciplines.

Many of the new technologies and government regulations, however, cannot be explained to farmers adequately within these time and media constraints. Increased integration and interpretation is required to help farmers deal with the current information explosion.

\section{The method}

A relatively new computer technology, expert systems (ES), offers a solution to both the decline in human and financial resources and the deliv- ery of increasingly complex horticultural and pest management technologies. True expert systems, simply stated, are computer programs designed to mimic the thought processes of a human. They require that technical knowledge be represented in a fashion that may be encoded by programmers. Knowledge may be represented via dependency networks (Travis and Latin, 1991; Travis et al., 1992) or by the use of IF/THEN statements; in which an action (THEN portion) is carried out provided the IF condition is fulfilled or met. Through the use of the expert system framework, it is also possible to represent heuristics or rules of thumb and to incorporate these into the problem-solving capabilities.

ES technology must, however, accomplish more than decisionmaking or problem solving programs to be used on the farm. Gum and Blank (1990) suggested that a hybrid or expanded expert system be developed to address multiple needs. We prefer to label these programs as decision support systems (DSS) rather than expert systems. DSS programs require a combination of computer tools: textual information, graphic capabilities, database management and storage applications, and the actual expert system application. Incorporating all these facets together in a single program requires close cooperation among multiple disciplines. DSS also more accurately reflects how the producer responds to problems. Producers must consider the interaction of cultural practices, the pest complex, and the impact on production economics.

Development and adoption of this technology has the potential to incorporate features of sustainable agriculture, integrated pest management, and integrated crop management into a single delivery mechanism that is readily and constantly available to assist fruit growers in making complex production decisions. These systems may also be used in the classroom to provide training to students and educators by allowing them to explore different orchard scenarios. Gum and Blank ( 1990) suggest that the expanded ES will become important extension delivery tools.

While ES have been conceptualized or developed in horticulture and agronomic crop production systems to prototype levels (Kable, 1991; Muttiah et al., 1988;Plantetal., 1989; 
Rogowski and Renquist, 1992), few have been released commercially, and little consideration has been given to the need for refinements after their initial release. One problem associated in horticultural applications is the need for timely revisions of chemical, regulation, and cultivar information. Changes in the knowledge base with development of new research also have not been considered. New rootstocks from Europe and the former Soviet Union will be released shortly, with only a limited amount of knowledge about their performance. The fruit industry also is rapidly adopting new cultivars to their production system. For example, the consequences and performance of the potential combination of the apple cultivar Braeburn on the Polish rootstock P.22 is unknown. This type ofinformation, however, must be incorporated rapidly if DSS are to have any lasting impact in the commercial farming community. Often the information may only consist of an expert's opinion; as such, the information can be relayed faster and to a larger audience through the use of DSS.

\section{Developmental considerations}

The development of DSS must be viewed as a continuing long-term project if it is to benefit industry. Unfortunately, in an academic setting, scientists are taught to think of research or extension projects as finite items. A research grant is received to solve one aspect of a problem, or to elucidate one area of a system, and is terminated once the objectives are accomplished. The DSS must be viewed as continually evolving entity. Too often the creation of the software program and accompanying manual is viewed as the end result. Programs for marketing and training are also needed to acquaint growers with this technology and to make sure they are knowledgeable enough to take full advantage of the depth of the DSS.

Just as extension specialists and consultants must update their knowledge, so must the knowledge and function of a DSS be updated. If a computer program is to be designated as a true ES or DSS, then, like our knowledge, it has to be changing, evolving, and increasing continually. Because of this need for evolution, adaptability, and improvement, DSS are ideally suited as tools for extension delivery programs. Extension specialists and consultants must continually update their knowledge and adapt their capabilities with each new season.

DSS' need to have broad geographical utility, because design, construction, testing, andimplementation may cost from $\$ 52,500$ (Gum and Blank, 1990) to $\$ 300,000$ (McClure, 1992). The difference between the two figures has two causes. First, the latter estimate incorporated the opportunity costs the time the domain experts spent in developing their knowledge in a form capable of being programmed; second, the former did not include the need for user/ evaluator costs. Development costs will also reflect the size and complexity of the problem and the number of cooperators involved.

\section{Regional cooperation is important}

Developing multiple systems applicable to only a single state or small region would not be economically or logically sound. DSS should ultimately be built with a regional or national scope. Regional knowledge needs to be pooled, since no single institution or individual can possibly be an expert in all aspects of a production system. The value of any DSS is proportional to the breadth of the knowledge base. Therefore, DSS promote and encourage interstate, interregional, and interdisciplinary efforts. This cross-political-line cooperation should be encouraged to a greater extent. The Penn State Apple Orchard Consultant (PSAOC) has demonstrated the advantage of using specialists from different areas to develop modules. The Fruit Thinning module being developed is a joint project between Penn State and the Appalachian Fruit Research Lab in Kearneysville, W.Va. (Crassweller et al., 1993). The leaf roller knowledge base was the result of collaboration with specialists at Cornell Univ. VITIS, a grape disease management expert system, is being developed cooperatively with input from specialists from Pennsylvania, New York, Ohio, and Michigan, and should be ready for field testing with growers in the 1993 growing season (Travis et al., 1992b). However, there is also the possibility of sharing DSS develop- ment knowledge internationally. The VITIS DSS development template was used as a model for AusVit-an Australian viticultural management expert system. AusVit was developed through the cooperation of 25 A ustralian viticulturists and an American coordinator. AusVit uses the same logic in the approach to decisions as VITIS with the insertion of Australian viticultural knowledge. AusVit integrates viticultural, entomological, and plant pathological decisionmaking to arrive at an integrated recommendation. AusVit will serve most of the Australian grape-producing regions. The prototype of AusVit has been de veloped and it will be field-tested with growers in 1993. It is intended that VITIS and AusVit will share information modules when appropriate (Travis, 1992c).

The PSAOC is now available commercially, and incorporates entomology, plant pathology, and horticulture in a single system to address production issues. The function and operation of the pest management portions have been described previously (Travis et al., 1992a). The system's first horticultural module was designed to assist growers tree-spacing decisions (Crassweller et al., 1989). The horticulture applications now include modules on weed control, foliar analysis interpre tation, trickle irrigation scheduling, determining the number of trees in a multi-row bed, and visual diagnosis of nutrient deficiencies. Other horticultural information indudes cultivar characteristics and weed identification. A module on frost protection system design, operation, forecasting, and orchard risk partitioning is also being developed in cooperation with agricultural engineers from Penn State and horticulturists from Penn State, North Carolina State Univ. and Univ. of Florida (Heinemann et al., 1993). This module could be incorporated into any DSS where frost protection is a concern for the crop.

A unique feature of the PSAOC is that it has been developed in cooperation with the end users, the commercial fruit growers. We know of no other horticulture computer systems that have incorporated suggestions for changes from the end users. However, this is a vital step if a DSS is ever to be used by commercial producers (Dillman, 1985). Other than the systems cited here, we are not aware of any 
systems on fruit production that have brought together individuals from multiple disciplines to address the production system as a whole, as recommended by Gerber (1989).

\section{Audience acceptance}

There are still unknown factors that affect the adoption of DSS by commercial farmers, extension agents, and consultants. Sullivan et al. (1989) cited evidence that $<10 \%$ of all farms in the United States currently use computers for management decisions. Bowser (1990) indicated that, although it would seem logical that large farm operations would be the most common end users of such systems, in reality they often had less management flexibility to use PSAOC.

Educational levels of the potential users undoubtedly play a role in the adoption of DSS. A recent survey of Pennsylvania field crop and apple producers, indicated that the average level of formal education of an apple farmer was 14 years, compared to 11 for a field crop farmers (Calvin et al., 1992). Thirty percent of the field crop farmers had 8 years or less of formal education. For this reason and because of the great amount of time spent by field crop farmers managing their livestock, it was concluded that DSS' in field crop production would most likely be used by the crop consultant and agricultural products industries. Therefore, the needs and capabilities of the end users must be considered in the necessity and design of the DSS. However, these educated assumptions as to whether future efforts in creation and distribution of this technology should be directed at the extension agents, consultants, or individual farmers, need further testing.

\section{Conclusions}

DSS can be an extremely valuable extension education tool, in light of current and future reductions in personnel and resources at land-grant universities. They can provide commercial producers easy, quick, and continuous access to vast amounts of information. DSS can promote an integrated approach to problem resolution as well as foster greater cooperation between disciplines. DSS can point to gaps in our knowledge where more research is needed. They can be used to instruct students in practical aspects of horticultural production and can promote the use of integrated pest management or integrated crop management.

There must, however, be better coordination between neighboring states or regions in developing these systems. Administrators and granting agencies must recognize that the development and utilization of DSS is not a 3-year research project with a definite ending point. Developers must target their audience and actively solicit and implement their needs and suggestions. Finally, sound compre hensive evaluation procedures of DSS must be developed before DSS are released commercially for on-farm decisionmaking.

\section{Literature Cited}

Bowser, T.A. 1990. Adoption of an expert system by apple growers: A test of a new model. MS thesis, Dept. of Rural Sociology, The Pennsylvania State Univ., University Park.

Calvin, D.D., E.G. Rajotte, and A. Harp. 1992. A survey of integrated pest management (IPM) practice adoption in Pennsylvania. Rpt. to the Pennsylvania Dept. of Agr., 3 Jan. 1992.

Crassweller, R.M., P.H. Heinemann, and E.G. Rajotte. 1989. An expert system on a microcomputer for determining apple tree spacing. HortScience 24:148.

Crassweller, R.M., G.M. Greene II, S.S. Miller and V. Eby. 1993. A chemical thinning expert system on the Penn State Apple Orchard Consultant expert system. Acta Hort. 313. (In press.)

Dillman, D.A. 1985. The social impacts of information technologies in rural North America. Rural Soc. 50:1-26.

Funt, R.C. and J.A.H. Nicholson. 1991. Comparison of grower advisory systems in Europe. HortScience 26:103-105.

Gerber, J.M. 1989. Changing roles within horticultural extension. HortScience 24:416-418.

Gum, R.L. and S.C. Blank. 1990. Design ing expert systems for effective delivery of extension programming. Amer. J. Agr. Econ. 72:539-547.

Heinemann, P.H., C.T. M orrow, J.D. M artsolf, R.M. Crassweller, and K.B. Perry.
1993. A decision support program for the protection of crops from frost. Acta Hort. 313. (In press.)

Kable, P.F. 1991. An expert system to assist orchardists in the management of rust disease of French prunes. Al Appl. in Nat. Res. Mgmt. 5:59-61.

M cCLure, J.E. 1992. Cost of developing an expert system in agriculture. Al. Appl. in Nat. Res. Mgmt. 5. (In press.)

Muttiah, R.S., C.N. Thai, S.E. Prussia, R.L. Shewfelt, and J.L. Jordan. 1988. A n expert system for lettuce handling at a retail store. Trans. Amer. Soc. Agr. Eng. 31:622-628.

Rogoyski, M.K. and A.R. Renquist. 1992. A decision support system for apple thinning in Colorado. HortScience 27:915-917.

Plant, R.E., F.G. Zalom, J.A. Young, and R.E. Rice. 1989. CALEX/ Peaches, an expert system for the diagnosis of peach and nectarine disorders. HortScience 24:700.

Poling, E.B., J.G. Richardson, and G.A. Benson. 1991. Extension and applied research in the European community and the United States. HortScience 26:943-944.

Sullivan, G. H., W.J. O oms, and G. E. Wilcox. 1989. Expert systems: Advanced artificial intelligence concepts for integrated crop management. HortScience 24:739-742.

Sullivan, G.H., W.J. Ooms, G.E. Wilcox, and D. C. Sanders. 1992. An expert system for integrated production management in muskmelon. HortScience 27:305-307.

Travis, J.W. and R.X. Latin. 1991. Development, implementation, and adoption of expert systems in plant pathology. Annu. Rev. Phytopathol. 29:343-360.

Travis, J.W., E. Rajotte, R. Bankert, K.D. Hickey, L.A. Hull, V. Eby, P.H. Heinemann, R. Crassweller, J. M cClure, T. Bowser, and D. Laughland. 1992a. A working description of the Penn State Apple Orchard Consultant, an expert system. Plant Dis. 76:545-554.

Travis, J.W., R. Pearson, M. Ellis, D. Ramsdell, C. Becker, D. Gadoury, D . D askopoulos, and A. M uza. 1992b. VITIS, a Northeast regional grape disease management expert system. Proc. of the Intl. Wkshp. on Grapevine Downy Mildew Modeling. Geneva, N.Y., 25-30. July 1991.

Travis, J. W. and A usV it Primary Cooperators. 1992c. AusVit: Australian viticultural management expert system. The Australian Grapegrower and Winemaker Annu. Tech. Issue 340:117-118. 